\title{
Determinants of Participation of Young Farmers with and without Disability in Agricultural Capacity-building Programs Designed for the Public in Uganda
}

\author{
David Agole ${ }^{1,2}$, Connie D. Baggett ${ }^{2}$, Mark A. Brennan ${ }^{2}$, John C. Ewing ${ }^{2}$, Edgar P. Yoder ${ }^{2}$, Sinfree B. Makoni ${ }^{3}$, \\ Matthew D. Beckman ${ }^{4} \&$ William Faustine Epeju ${ }^{1}$ \\ ${ }^{1}$ Department of Agriculture, Kyambogo University, Kampala, Uganda \\ ${ }^{2}$ Department of Agricultural Economics, Sociology and Education, College of Agricultural Sciences, The \\ Pennsylvania State University, University Park, PA 16802, USA \\ ${ }^{3}$ Department of Applied Linguistics, College of Liberal Arts, The Pennsylvania State University, University Park, \\ PA 16801, USA \\ ${ }^{4}$ Department of Statistics, The Pennsylvania State University, University Park, PA 16802, USA \\ Correspondence: David Agole, Department of Agriculture, Faculty of Vocational Studies, Kyambogo University, \\ P.O Box 1 Kyambogo, Uganda. Tel: 256-414-286-242. E-mail: dagole@kyu.ac.ug
}

Received: October 24, 2020 Accepted: January 21, 2021 Online Published: April 15, 2021

doi:10.5539/sar.v10n2p74 URL: https://doi.org/10.5539/sar.v10n2p74

\begin{abstract}
Participation of young farmers with disabilities in agricultural capacity-building programs in their communities is important as a poverty reduction strategy for people with disabilities in Uganda. This research study comparatively examined participation of young farmers with and without disabilities in capacity-building programs designed for the public in Northern and Eastern Uganda. The study employed a comparative, mixed methodology, cross-sectional research designs involving 774 young farmers composed of 388 with disabilities and 386 who had no disabilities. The sample selection strategies involved the use of a stratified, and random sampling techniques. This research utilized an interviewer-administered paper survey in collecting data. Descriptive statistics and regression analyses were used in analysing quantitative data. The findings indicate that young farmers with disability and being contacted face-to-face were less likely to participate in community capacity-building programs. In contrast, Northern Uganda, those contacted in a group setting, application of sign language interpretation, being female, and having supportive training staff increased the chances of their participation in community capacity-building programs.
\end{abstract}

Keywords: agriculture, capacity-building programs, disability, participation, youth with and without disability

\section{Introduction}

\subsection{Disability Status in Uganda}

Young farmers with disabilities in Uganda tend to be excluded from participation in capacity-building programs that would make a difference in their wellbeing (Department for International Development [DFID), 2014, 2015; Peter, 2006; Vornholt, Uitdewilligen \& Nijhuis, 2013). For example, categories of people with disabilities include that of young farmers who mostly live in rural and remote areas of Uganda. Marginalization and exclusion from education, health, and agricultural programs meant to improve the livelihood and well-being of community members characterize young farmers with disabilities in Uganda (DFID, 2015). Having been largely excluded from formal education, young farmers with disabilities experience low production and productivity in the livelihoods in which they engage, especially in subsistence production agriculture (UNESCO, 2018). Thus, $80 \%$ of the people with disabilities in northern and eastern Uganda live in chronic poverty (Uganda Bureau of Statistics, 2007).

Most young farmers with disabilities engage in production agriculture, but do not access agricultural extension services meant to provide young farmers with knowledge and skills, information, production inputs and technologies (DFID, 2014, 2015). Farmer groups need agricultural extension and advisory services in Uganda but the high level of stigma attached to disability forces young farmers with disabilities to undertake casual and 
risky jobs shunned by people without disabilities. Given the high level of discrimination and exclusion, young farmers with disabilities primarily derive their livelihood and well-being from subsistence agriculture and informal jobs such as collecting garbage, cleaning premises, casual labor at farms, and begging for alms in urban settings within their communities (DFID, 2014, 2015). Most young people with disabilities engage in less gainful jobs and receive low pay compared to young farmers without disabilities (Milner et al., 2015). Thus, poverty and food insecurity characterize the daily life of young farmers with disabilities (Yeo, 2005).

Studies point to a relationship between chronic poverty and disability in most developing countries (Eide \& Ingstad, 2013; Lwanga-Ntale, 2003; Yeo, 2005). An estimated 50,000 people, including 10,000 people with disabilities, die every day because of chronic poverty (Yeo, 2005). Poor people tend to have disabilities and are most likely to be poor. Their poverty limits their access to education and health (Lwanga-Ntale, 2003; Whelan et al., 2009) and recreational services (Devine, 2012), and experience acute food shortages and poor nutrition (Lwanga-Ntale, 2003). Their families and communities bear the burden of the high costs of care (DFID, 2015; Emmett, 2006; Yeo, 2005).

Northern Uganda experienced a protracted civil war between the Lord's Resistance Army (LRA) and the Government of the Republic of Uganda between 1986 and 2004. This war had catastrophic effects on human physical, mental and emotional health, and the wellbeing of people and communities (Carter, 1997; Forge, 1997). The Northern and Eastern Uganda civil wars displaced people from their communities, and caused loss of life, injuries, and loss of livelihood (Beisland \& Mersland, 2014). The political climate in Uganda is characterized by civil conflict that lasted over 20 years, with after-war effects such as increasing the number of people with disabilities, land conflicts among families and with the state, diseases, and a breakdown of social services (education and health). Post-war disabilities and psychological trauma affect many (Grant, 1997). Globally, the effects of war are more pronounced on children and women, with one child in every 200 traumatized by war.

Development agencies, practitioners, and human rights bodies recognize that regardless of where people with disabilities live, they are more likely to be poor, vulnerable, and marginalized (Eide \& Ingstad, 2013; Lwanga-Ntale, 2003; Yeo, 2005; Mpofu \& Shumba, 2013). Notably, Article 32 of the United Nations (UN) Convention on the rights of people with disabilities mandates that international cooperation and international development programs be inclusive of and accessible to people with physical and mental impairments (DFID, 2015; Wolbring et al., 2013). As argued by Wolfensohn (2002), former President of the World Bank, the UN Millennium Development Goals and the current Sustainable Developed Goals will not be met unless disability issues are addressed (Wolbring et al., 2013).

Disability refers to a social consequence of the possessed impairment attributed to inequities faced by people with disabilities due to community structure (Whelan et al., 2009; Yeo, 2005), which emanates from a complex system of restrictions and barriers imposed on people with physical and mental impairments. The restrictions and barriers tend to impede the ability and rights of people with disabilities to enjoy opportunities and benefits accessed by people without disabilities (Friesen et al., 2010; Siddiqua et al., 2012; Yeo, 2005). Disabilities can occur in the form of physical, sensory, intellectual, mental or behavioral condition (Friesen et al., 2010; Yeo, 2005), an injury, illness, or inborne (Whelan et al., 2009).

According to the Uganda Police Force annual crime/traffic reports for 2010 through 2013, accidents constitute the leading cause of death and disability in Uganda. Similar reports by World Health Organization (2013) and Gukande et al. (2009), attribute acquired disability to road accidents that are common in Uganda because of the poor state of roads. In addition, most farmers lack protective wear, thus, they are facing increased risk to injuries from farm implements, sharp objects, agrochemicals, and snakebites.

\subsection{Meaning and Topology of Participation}

Participation refers to the process of attendance and active involvement of people in situations and decisions that affect themselves and their community (Checkoway \& Gutierrez, 2008). In this study, participation refers to shared influence and the responsibility of participants to become actively involved in program activities such as decision making and feeling of belonging to those programs and communities (Head, 2008; Wagner III, 1994). Thus, participation entails informing, consultation, involvement, collaboration, and empowerment of the target participants so as to build their capacity for improved well-being (Wagner III, 1994). In addition, participation takes three dimensions: as contribution, as organization, and as empowerment. Participation as contribution refers to participation of community members through labor, cash, and land, among others. Participation as organization refers to creation of appropriate structures to facilitate participation by targeted people. While participation as empowering refers to involving marginalized and underserved groups and communities to develop power and influence to make decisions and have control over programs meant to benefit them (World 
Health Organization, 1991). Critical, therefore, to the definition of participation is that it targets vulnerable, underserved, and excluded people to build their capacity to make decisions and have control over all programs intended to benefit them. Participation takes a number of forms including: informing people with balanced and objective information, consulting people and providing feedback, involving and working directly with communities, collaborating and partnering with groups or communities in decision making, and empowering and ensuring that the participants retain control over decisions that affect them (World Health Organization, 2008). It is, therefore, important to create spaces that enable and encourage participation by vulnerable and excluded groups such as people with disabilities. However, a critical gap exists in factors that influence participation by people with disabilities in capacity-building programs in communities.

Participation involves eight levels: 1) manipulation, 2) therapy, 3) informing, 4) consultation, 5) placation, 6) partnership, 7) delegated power, and 8) citizen control (Sherry, 1969). While the presence of eight levels seems oversimplified, they help to illustrate something that is often omitted by development programmers to the disadvantage of targeted program participants (Sherry, 1969). Most often, development practitioners misconstrue manipulation as if people have been involved in planning, yet the resource-poor have not been engaged/have not participated in either planning or decision-making (Sherry, 1969). Information and consultation allow the targeted poor to hear and to have a voice in program planning and decision-making. Participation by vulnerable and excluded groups from capacity-building programs in communities tends to be facilitated by less stratified communities, a supportive environment, and conducive policy framework (Anaby et al., 2013; World Health Organization [WHO], 1991).

\subsection{Role of Programs in Capacity Building of People with Disabilities}

As with all people, when people with disabilities participate in capacity-building program activities, they develop skills, competencies, and social networks (Deutsche Gesellschaft fur Technische Zusammenarbeit [GTZ] 2005; WHO, 2008). In addition, when people with disabilities participate in programming activities their mental and physical health is enhanced and they develop a feeling of belonging to the community, while providing meaning and purpose in life. Meaningful, active, and rewarding community participation is the main goal of capacity-building programs. Participation is important to the well-being of people with disabilities (WHO, 2008). People with disabilities are not meaningfully included in community development activities due to the demands required to be effective in making fundamental changes in organizational policies, and capacity building of personnel, among others. In 2005, a report of a meeting between USAID, the National Union of Persons with Disabilities in Uganda (NUDIPU), the Kampala Disabled Persons Business Association, and Action on Disability and Development (ADD) showed that organizations for the disabled had difficulty accessing funding because their program interests did not align with the donor community's priorities (Albert et al., 2005).

In the above scenario, these organizations were not funded because the funding interests of USAID were perceived to be different from those of people with disabilities. The question is this: how many other organizations for people with disabilities in the world may have and may be continuing to experience such funding dilemmas? Failure to obtain funding or support constrains people with disabilities from pursuing their interests and needs. Capacity building for the disabled requires hands-on learning and observation of innovative agricultural practices in the case of farmers/farm workers. Access to these resources can promote skill development in problem solving through participatory learning and group activities designed to empower farmers as well as to promote social cohesion through increased cooperation (Phillips et al., 2014).

A few organizations are involved in and have championed research and capacity building for people with disabilities and their support organizations in developing countries. The best example, so far, is the United Kingdom's Department for International Development (DFID) as the first agency to issue a paper on the status of people with disabilities, and the United States Agency for International Development (USAID), which has continuously mainstreamed disability issues in programs and organizations and supported those agencies. Such mainstream activities that address the plight of people with disabilities include opportunities to support more-focused activities, direct support of organizations for the disabled, and support of all initiatives aimed at building capacity people with disabilities. The reason for this support is that people with disabilities lack human development and capacity building opportunities, such as educational and vocational training opportunities (DFID, 2000; Siddiqua et al., 2012). People with disabilities must be involved in all aspects of capacity-building programs such as planning, advocacy of training programs, and delivery of the capacity-building programs at individual, group and systemic levels. Lewis (2010) added that capacity-building programs could elicit successful outcomes when people with disabilities constitute part of the consultative and delivery process as agents for socioeconomic change. 
In practice, community development programs are meant to address equity criteria by targeting people with disabilities among others. Unfortunately, however, community programs tend to prioritize effectiveness criteria to maximize the impact of the program as opposed to equity criteria, which is all-inclusive. The effectiveness criteria mostly address participation of more resourced, educated and socially networked individuals. Most programs, however, tend to adequately meet effectiveness criteria as opposed to equity inclusion. This stems from either conflicting target criteria or participant-selection mechanisms that favor the elite or capture the need for a minimum level of social and economic capital (Vornholt et al., 2013). The poor tend to benefit more when they participate directly in programs than when those programs are only knowledge-based (Phillips et al., 2014). Capacity building for people with disabilities in relevant areas also serves to increase their knowledge and skills through informal learning, learning by doing, and lifelong learning while building the capacity of organizations supporting people with disabilities (Wolbring et al., 2013). A study carried out in Zimbabwe pointed to the exclusion of people with disabilities from access to community entrepreneurial programs, despite the fact that those with disabilities were aware of the program's existence in the community (Mpofu \& Shumba, 2013). People with disabilities have lower expectations because they are more disadvantaged in the labor market (Pagan-Rodriguez, 2015). The presence of a disability has been found to contribute to lower job satisfaction. Sometimes further participation by people with disabilities in capacity-building programs does not translate into increased rewards because of the already existing stigma employers and other workers portray against people with disabilities

Even when people with disabilities supposedly participate in capacity building through community development programs, their attendance or non-attendance, or dropout rate is influenced by factors such as accessibility and relevance of the program to their needs (Phillips et al., 2014; Vornholt et al., 2013). Ineffective program implementation or economic constraints, and perceived returns and opportunity costs of attendance also influence the participation of people with disabilities in community capacity-building programs. However, sometimes participants drop out due to a failure to achieve individually anticipated expectations such as loans, cash or payment in kind for their attendance (Phillips et al., 2014). Participant expectations tend to be guided by those occasions in which development programs with incentives attract participation or require inputs for individuals to implement the program. Therefore, the absence of payment or incentives elicits a negative reaction that discourages participation. In addition, if participants feel that the program is going to encroach on their time for other socio-economic activities and the distance to attend the program is long, they are most likely to drop out or irregularly attend (Phillips et al., 2014).

Many challenges characterize Uganda's extension service delivery. There is very high farmer to extension educator ratio ( 3,000 to 1$)$, hard to reach remote and rural communities with poor communication, and poorly facilitated extension educators with very low morale. Thus most young farmers remain unreached by agricultural extension services (Barungi et al., 2016). Barungi et al. add that since 1960, Uganda's extension system has experienced several reforms, whose effect further alienated vulnerable and underserved groups of farmers such as those with disabilities. The ultimate blow on the Uganda's extension system was a decree by the executive arm of the Government of Uganda in 2014, summarily phasing out frontline extension educators and replacing them with military personnel (Rwakakamba \& Lukwago, 2014).

\subsection{Purpose and Objectives}

The primary purpose of this paper is to comparatively examine factors that influence participation of young farmers with and without disabilities in capacity-building programs designed for the public in Northern and Eastern Uganda. More specifically, it assesses the influence of mode of contact with extension educators, use of accommodation facilities, disability status, region of location, supportive program personnel and gender on participation and active participation of young farmers with and without disability in agricultural capacity building programs in Northern and Eastern Uganda.

\subsection{Theoretical Framework}

The study on which this paper is based was informed by an integration of the social model of disability (Burton, 1993) and community interaction theory (Wilkinson, 1991). This study used the interactional theory to gain insights into the influence of interactions among individuals on participation in capacity-building programs of young farmers with and without disabilities. The theory postulates that a community is comprised of social fields, which allow people to connect and interact with one another to form community fields (Pigg, 1999; Wilkinson, 1991). From this perspective, interaction of community members through the social fields allows individuals to access information on existence of capacity building programs and get involved in those programs in the hope of attaining benefits that accrue to participating individuals. Therefore, the strength or weakness of the social fields 
formed among individuals is critical for determining participation in capacity building programs. The social model on which this study was focused, refers to disability as a social consequence of the possessed impairment attributed to structural inequities that most communities impose on people with disabilities (Burton, 1993), which infringe on their rights to benefit from programs targeting the wider community.

\section{Method}

\subsection{Study Area and Research Design}

This study was completed in the Northern and Eastern regions of Uganda because they have the highest disability and poverty rates (The Republic of Uganda \& UNICEF, 2014). Northern Uganda has a total population of 7,188,139 people and Eastern Uganda 9,042,420 people (Bureau of Statistics, 2015). Reliable data on the number or percentage of people with disabilities in Uganda does not exist; however, existing estimates range from four percent to twenty percent. It is, therefore, difficult to obtain an accurate frame to base the study sample on.

The Northern and Eastern regions of Uganda have experienced protracted civil wars since the mid-1980s to early 2000s (Beisland \& Mersland, 2014). The civil war resulted in numerous physical, emotional, and traumatic disabilities on the people of northern and eastern Uganda. The civil wars displaced people from their communities, with many living in concentration camps for over 15 years in northern and about seven years in eastern Uganda.

This study employed a multidimensional model of research design involving a comparative, descriptive cross-sectional survey combined with mixed qualitative interview methods/strategies (Niglas, 2010). Comparative research examines similarities and differences between two or more entities, along a common point (Crossley \& Broadfoot, 1992). The data collected represents cross sectional research information since the quantitative data identifies characteristics of a sample to determine population parameters at a specific point in time (Urdan, 2010). In this study, the comparison is between young farmers with disabilities and without disabilities. This study utilized mixed methods/methodologies involving a combination of quantitative and qualitative approaches (Cameron, 2011; Creswell \& Plano Clark, 2011).

\subsection{Study Population and Sample}

The sample size of 774 young farmers with and without disabilities was determined using a sampling table of $95 \%$ confidence, with a 5\% margin of error. This study included 774 young farmers, with 388 having disabilities and 386 without disabilities. The sample included 493 selected from Northern Uganda (258 with disability and 235 without disability) and 281 from Eastern Uganda (130 with disabilities and 151 without disabilities). The ages ranged between 16 and 45, and all were involved in the agricultural sector.

The study used multi-stage-stratified sampling to identify districts, sub counties. The stratum was region (Northern Region or Eastern Region). Criterion based on purposive selection was used in selecting the northern and eastern regions of Uganda because the two regions have the highest disability rates and highest poverty levels in Uganda (Bureau of Statistics, 2015). The stages represented districts and sub counties. A list of all districts in each region constituted a sampling frame from which simple random sampling, with replacement, was used in selecting at least three districts in a region. At the district level, a list of all people with disabilities was obtained from the National Union of Disabled Persons of Uganda (NUDIPU) district offices, which served as the sampling frame for individuals. Once the districts were selected, individual names of young farmers in each district were obtained. Then simple random sampling was used to give all young people with and without disabilities an independent and equal opportunity to be selected to participate in the study (Urdan, 2010; Dillman et al., 2014). The sample was generated by assigning numbers to a frame of all young farmers with disabilities in Northern and Eastern Uganda. By using a random number generator on Microsoft Excel, the respondents were randomly selected to constitute the study sample. Thus, the unit of analysis for enumeration was the individual young farmer with or without a disability.

Personnel at the National Union of Disabled Persons of Uganda (NUDIPU) acted as the point of entry to access young farmers with disabilities because of their knowledge and experience as a disability organization that is closely working with people with disabilities in communities. NUDIPU has offices that span national and district levels, in line with Uganda's decentralized system of governance of bringing services closer to the people to improve their participation in addressing development challenges affecting themselves.

\subsection{Instrumentation}

The interviewer-administered paper survey was developed for collecting quantitative data from young farmers with or without disabilities. The survey contained four main sections including socioeconomic factors, 
participation in programs, well-being, and demographic characteristics of the respondents. The questionnaire was reviewed for content validity. In addition, the paper survey was pilot tested by administering it to 20 young farmers with or without disabilities. The pilot test participants were not included in the actual study data. Cronbach Alpha was used for determining the internal consistency of the items, which were used in forming summated subscales. The survey instrument consisted of some items with a nominal response scale as; Yes and No, Cronbach Alpha $(\alpha)$ was used for testing internal consistency of the summated scales and ranged between $\alpha=.535$ and $\alpha=.919$. The reliability analysis for accommodation facilities ( 4 items) $\alpha=.937$.

The focus group discussions collected data not gathered by the questionnaire for verifying and further developing an understanding of findings from the quantitative data. The focus group checklist explored self-image, perception of the family members, community members, and program officers about a person with disability and identifying coping mechanisms for disability and social exclusionary challenges at the family, community, and program levels. Other areas of focus included capacity building programs participated in and whether they were public or private. The focus group checklist was reviewed and field-tested through a group discussion with social workers working with disability organizations in Northern Uganda. For better comprehension of the checklist, some questions were rephrased or deleted. Based on the two categories of discussants, young farmers with and without disabilities, two focus group checklists were developed for comparison, only differentiated by the phrase with and without disability.

\subsection{Data Collection}

The data collection process began by consulting with personnel at the District Union for Disabled Persons of Northern and Eastern regions of Uganda to secure permission to carry out research involving young farmers with disabilities. The purpose of the consultation with NUDIPU personnel was for obtaining support in identifying and mobilizing potential research enumerators and respondents from Gulu, Amuru, Nwoya, and Omoro, Kumi, Bukedea, and Ngora districts. Research enumerators that assisted in the administration of the survey were trained for four days to reduce potential measurement error as much as possible in the data collected and to increase the efficiency and effectiveness of the research process.

Furthermore, Gulu Community Vocational Institute, which is implementing DYNAMIC project of Agriculture, which targets youth in Northern Uganda was requested to provide support because of their experience and knowledge in working with people with disabilities and young farmers in northern Uganda. However, in eastern Uganda with less developed disability formalized structures, the study used Local Council (LC) administrative structures to identify research enumerators and respondents.

Quantitative data were collected from young farmers with or without disabilities using two interviewer-administered paper surveys that are only differentiated by the demographic (disability) variable to allow comparison of young farmers with or without disabilities. Young farmers with disabilities were in the categories of: speaking, hearing, walking and handling, visual, and burns/deformities; and mental and epilepsy disabilities; albino and little people. The paper survey was administered by five research enumerators trained by the principal investigator in accordance with standards approved by Penn State University Institutional Research Board. Since most people with disabilities cannot read nor write, the questions were translated into Luo and Ateso dialects for comprehension. The research enumerators included social workers with disability organizations, youth with disabilities, and sign language interpreters for the benefit of young farmers with hearing and speaking disabilities. Quantitative data were collected in January 2017 from 774 respondents, with 493 (258 with disability and 235 without disability) from Northern and 281(130 with disabilities and 151 without disabilities) from Eastern Uganda. Through disability organizational structures, appointments were made with selected respondents and interview-paper survey administered in situ. The questionnaires were administered in the households of young farmers with disabilities in one sitting.

\subsection{Data Analysis}

Data for young farmers with or without disabilities were separately collected and entered in SPSS as separate data files. After cleaning the data and checking for missing data patterns, if any, the two data sets were merged with identifier variables created regarding disability status and region. No personal identifiers (names, codes, etc.) were assigned to specific individuals in the data files. The Statistical Package for Social Science (SPSS) was used to analyze quantitative data. The study employed descriptive statistics and binary logistic regression was used to simultaneously examine the collective influence of disability status, region and mode of contact on whether the young farmer was or was not asked to participate in community capacity building programs. The descriptive statistics for each of the variables were included in the analysis for the first logistic regression.

Qualitative data for young farmers with and without disabilities were analysed by generating codes and themes. 
This involves systematically reducing data (chunks of information) to open codes and axial codes, then developing themes from the codes, and identifying keywords and using the surrounding words to understand the underlying meaning of the keyword to explain the occurrence of a phenomenon (Onwuegbuzie \& Collins, 2007). The study employed the qualitative data-coding framework recommended by Saldana (2008) for coding and analysis procedures of the qualitative data.

\section{Results}

It is important to note that participation in capacity building should target the vulnerable, underserved and excluded people such as those with disabilities to build their capacity to make decisions and have control over all programs.

The respondents were asked about their participation in community training programs in the last five years because most programs targeting both people with and without disabilities were implemented in the last five years. Binary logistic regression was used to simultaneously examine the collective influence of disability status, region and mode of contact on whether the young farmer was or was not asked to participate in community capacity building programs. Thus, the investigators examined the determinants of participation of young farmers in capacity building programs. Table 1 summarizes the descriptive statistics for each of the variables included in the analysis for the first logistic regression. Approximately $31 \%(\mathrm{~N}=88 / 128)$ indicated they had been contacted via a face-to-face conversation and 35\% ( $\mathrm{N}=45 / 128)$ indicated they had been contacted in a group setting.

Table 1. Summary Descriptive Statistics for Variables used in Logistic Regression Analysis

\begin{tabular}{llll}
\hline Variable & Dummy Coding & Frequency & Percentage \\
\hline Disability & $0=$ No Without Disability & 386 & 68.7 \\
& $1=$ Yes With Disability & 176 & 31.3 \\
& & 562 & 100.0 \\
Region & $0=$ Eastern & 183 & 32.6 \\
& $1=$ Northern & 379 & 67.4 \\
Contact by Face-to-Face & & 562 & 100.0 \\
& $0=$ No & 88 & 68.8 \\
Contact in Group Setting & $1=$ Yes & 40 & 31.2 \\
& & 128 & 100.0 \\
\multirow{2}{*}{ Asked to Participate in Community Programs } & $0=$ No & 83 & 64.8 \\
& $1=$ Yes & 45 & 35.2 \\
& & 128 & 100.0 \\
& $1=$ No & 316 & 56.2 \\
& & 246 & 43.8 \\
\hline
\end{tabular}

The logistic regression results indicated there was an acceptable model fit (discrimination among the two groups of the dependent variable) on the basis of the four independent variables $\left(X^{2}=48.00, \mathrm{p}<0.001\right)$. Of the four predictor variables two were found to be statistically significant (disability status $p=0.001$; face-to-face contact $p=0.013)$. This indicates the odds that those with a disability were $95.4 \%$ less likely compared to those without disability $(\mathrm{p}<0.001)$ to participate in community capacity building programs. An odd of .046 indicates that the outcome labelled a 1 (not asked to participate in community programs) is 0.046 times as likely with a one-unit increase in the predictor variable when controlling for the influence of the other three predictor variables. Being contacted via face-to-face conversation had an $\operatorname{Exp}(B)$ value of 0.178 .

The four variables collectively were somewhat acceptable regarding the discrimination between the two groups of the dependent variable. The variables correctly classified $89 \%$ of those individuals that have been contacted in the last 5 years to attend any community training programs; whereas, the model correctly classified $71.4 \%$ who were not contacted to attend community training programs. It must be emphasized that this analysis is conducted using listwise deletion of missing cases, and thus only 128 young farmers were used in the logistic regression analysis in Table 2.

Table 2 indicates having a disability reduced the odds of a young farmer's participation in capacity-building programs by $95.4 \%(p<0.001)$. This implies that young farmers with disabilities are less likely to participate in capacity building programs meant to benefit all community members. In addition, being located in Northern Uganda increased the odds of a young farmer to participate in capacity-building programs in their communities by a factor of 3.646 compared to young farmers in Eastern Uganda $(p=0.060)$. Thus, young farmers in Northern 
Uganda experience more opportunities of participating in capacity-building programs compared to their counterparts in Eastern Uganda. Furthermore, face-to-face contact decreased odds of young farmer participation in capacity-building programs in their communities by $82.2 \%(p=0.013)$, while contact in a group setting increased the odds by $73.3 \%(p=0.383)$. According to focus group discussions in Northern Uganda, young farmers have formed groups to access capacity-building services and increase their ability to advocate for service delivery.

$\log ($ odds of participation $)=-2.369-3.085$ (disability) +1.294 (Northern Uganda) -1.727 (face-to-face $)+$ 0.550 (group meeting)

Table 2. Participation Regressed on Disability, Region, and Selected Modes of Contact

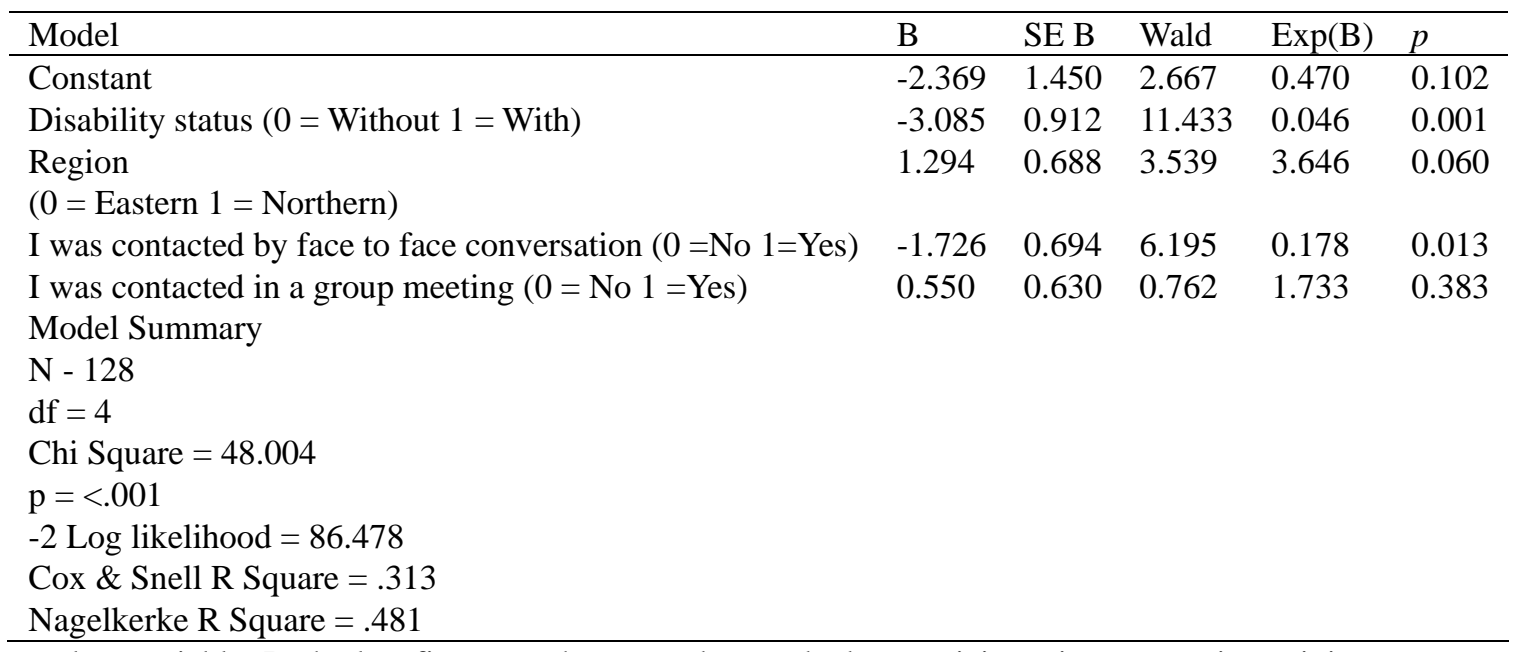

Dependent variable: In the last five years have you been asked to participate in community training programs is coded $0=$ Yes, asked to participate and $1=$ No, not asked to participate.

Table 3. Active Participation Regressed on Disability Accommodations and Gender

\begin{tabular}{llllll}
\hline Model & B & SE & Wald & $\operatorname{Exp}(\mathrm{B})$ & $p$ \\
\hline Constant & -4.210 & 0.767 & 30.104 & 0.015 & $<0.001$ \\
Sign language interpretation $(0=\mathrm{No})$ & 0.387 & 0.093 & 17.403 & 1.472 & $<0.001$ \\
Supportive training staff $(0=\mathrm{No})$ & 0.462 & 0.142 & 10.601 & 1.587 & $<0.001$ \\
Gender $(0=$ Female $)$ & 1.290 & 0.362 & 12.691 & 3.633 & $<0.001$
\end{tabular}

Dependent variable: In the last five years, have you worked with any extension educator on issues related to your agricultural enterprises

Table 3 indicates that sign language interpretation increased the odds of young farmers with disabilities to work with extension educators on issues related to their agricultural enterprises by $47 \%(p<0.001)$. This implies that young farmers with disabilities are more likely to participate in capacity-building programs when the training implementers provide sign language interpretation. Thus, application of sign language interpretation in capacity-building programs promotes inclusion, which enhances young farmers' feeling of belonging to and participation in capacity-building programs. In addition, disability-supportive training staff increased the odds of participation of young farmers with disabilities in capacity-building programs by 58\% $(p<0.001)$.

Furthermore, Table 3 shows that being female increased the odds of a young farmer's participation in capacity-building programs by a factor of 3.633 compared to males. In Uganda, most development agencies target women participation in capacity-building programs due to their pivotal role in household nutrition and performing over $80 \%$ of agricultural activities.

Reduced Regression Equation:

Log $($ odds of participation $)=-4.210+0.387($ sign language interpretation $)+0.462($ supportive training staff $)+$ 1.290 (female) 


\section{Discussion and Conclusion}

\subsection{Discussion}

Possessing a disability reduced the odds of a young farmer's participation in capacity-building programs by $95.4 \%$ $(p<0.001)$. This implies that young farmers with disabilities are less likely to participate in capacity building programs meant to benefit all community members. In addition, being in Northern Uganda increased the odds of a young farmer to participate in capacity-building programs in their communities by a factor of 3.646 compared to young farmers in Eastern Uganda $(p=0.060)$. Thus, young farmers in Northern Uganda experience more opportunities of participating in capacity-building programs compared to their counterparts in Eastern Uganda. Furthermore, face-to-face contact decreased odds of young farmer participation in capacity-building programs in their communities by $82.2 \%(p=0.013)$, while contact in a group setting increased the odds by $73.3 \%$ ( $p=$ 0.383). Sign language interpretation increased the odds of young farmers with disabilities working with extension educators on issues related to their agricultural enterprises by $47 \%$ ( $p<0.001$ ). In addition, the presence of disability-supportive training staff increased the odds of young farmers with disabilities working with extension educators on issues related to their agricultural enterprises by $58 \%$ ( $p<0.001$ ). Being female increased the odds of young farmers participating in capacity-building programs by a factor of 3.633 compared to males.

Young farmers with disabilities largely remain excluded, stigmatized, and marginalized from participation in capacity-building activities meant for the public due to the nature of their bodies and socio-cultural constructs (Abimanyi-Ochom et al., 2014). It is very difficult for people with disabilities to negotiate entry to capacity-building activities in communities, resulting in a low public status. The low level of formal education among young farmers with disabilities is largely due to their social exclusion in communities and from formal education opportunities that would empower them. The social exclusion of young farmers with disabilities is due in part to the very low value attached by families and communities to a person with a disability - in other words; these individuals may be viewed as a burden with less/low value to family and community development. Attempts to enter capacity building programs to attain knowledge and skills and competencies for production agriculture usually result in drop-out due to a lack of accommodation facilities; further, most program personnel are not prepared psychologically, emotionally, and technically to help young farmers with disabilities fit into the program environment.

According to the focus group discussion, young farmers with disabilities tend to navigate family, social groups, and wider community settings to access community capacity building programs. Within each of the social structures that young farmers need to navigate, there are unique challenges that those with disabilities face. Here are some examples, as articulated by individuals in the research sample.

[Accessing group support for people with disabilities:] When programs come for people with disability, our leaders come and register us and during implementation of the programs, other people benefit on our behalf. People with disabilities are used only for accountability purposes. [A man from Kumi district with a visual disability.]

[Difficulty joining community capacity-building programs:] In my area if you do not know anybody in any program, you cannot benefit anything. Sometimes you have to bribe your way into these programs like the youth livelihood program. Another alternative is to have a friend or relative in the program otherwise you are left out. [A man from Kumi district with a visual disability.]

Depending on the nature and severity of the disability, community members tend to attribute its manifestation to family and especially the parents of the person with a disability. The negative perception that families and communities possess against people with disabilities also transcends community capacity building programs. Many factors such as social stereotypes, stigmatization, and functional challenges posed by the nature of disability impede participation of people with disabilities in capacity-building programs in communities. This condition renders many disabled unable to avoid adverse economic conditions, forcing them to experience lives of poorer quality than that endured by the nondisabled poor.

According to focus group discussions in Northern Uganda, young farmers have formed groups to access capacity-building services and increase their ability to advocate for service delivery. Northern Uganda has well developed disability organizational structures and many capacity-building programs because of the 20-year civil war in Northern Uganda that attracted many development agencies that implemented various agricultural capacity building programs, some of which only targeted people with disabilities. During the civil war in Northern Uganda, most people lived in internally displaced people's settlements, in which they closely interacted together, thus creating a social bond and reliance on one another since the people with and without disabilities 
were faced with similar challenges.

Most agricultural capacity building programs tend to target women because of their pivotal role in socioeconomic transformation of households. Most women farmers with and without disabilities perform over $80 \%$ of farm work, thus carry the burden of providing food and nutrition and income for their households. The conceptual framework of the empirical findings is summarized in Figure 1.

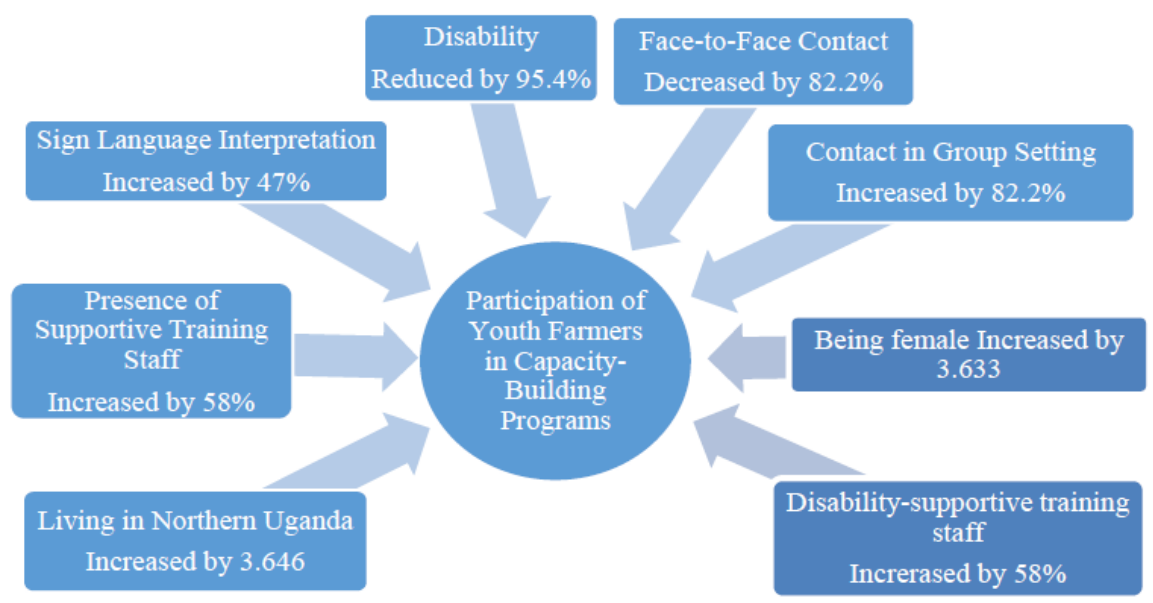

Figure 1. Conceptual Framework as Shown by Empirical Findings

\subsection{Conclusion}

Having a disability reduces a young farmer's opportunity to participate in capacity-building programs. Young farmers with disabilities are more likely to be contacted in group settings rather than via face-to-face - an indication of social exclusion and discrimination that restricts them from participation in capacity-building programs compared to young farmers without disabilities. Thus, unless they are in a group setting, young farmers with a disability are less likely to be asked by extension or community educators to participate in capacity-building programs. However, access to sign language interpretation and supportive-training personnel and being in Northern Uganda improves or enhances participation among young farmers with disabilities in capacity-building programs.

\subsection{Recommendations}

Agencies that fund community development should demand evidence of disability-inclusive programming as one criterion for funding capacity-building programs to enhance inclusive participation of young farmers with disabilities in community capacity-building programs. Moreover, concerted effort of community leaders and programmers should support and enforce disability policies to promote equity in farmer participation in capacity-building programs. Disability issues for young farmers need to be brought to the forefront for extension educators, community workers, and community members. Additionally, disability sensitive programming should be incorporated into extension training curricula.

\section{Acknowledgements}

Thanks to Fulbright, AgrAbility Project for Pennsylvanians, UNESCO Penn State, and Kyambogo University for the scholarship and funding this study. Thanks to young farmers with and without disabilities who participated in the survey and focus group discussions, and the staff of National Union for Disabled Persons in Uganda. Finally, thanks to reviewers who reviewed this manuscript.

\section{References}

Anaby, D., Hand, C., Bradley, L., DiRezze, B., Forhan, M., DiGiacomo, A., \& Law, M. (2013). The effect of the environment on participation of children and youth with disabilities: A Scoping review. Journal of Disability and Rehabilitation, 35(19), 1589-1598. https://doi.org/10.3109/09638288.2012.748840

Barungi, M., Guloba, M., \& Adong, A. (2016). Uganda's agricultural extension systems: How appropriate is the single spine structure. Economic Policy Research Center, 16, 1-34.

Beisland, L. A., \& Mersland, R. (2014). Income characteristics and the use of microfinance services: evidence 
from economically active persons with disabilities. Disability \& Society, 29(3), 417-430. https://doi.org/10.1080/09687599.2013.816625

Burton, L. (1993). The struggle for citizenship: The case of disabled people. Disability \& Society, 8, 235-248. https://doi.org/10.1080/02674649366780251

Cameron, R. (2011). Mixed methods research: The five Ps framework. Journal of Business Research Methods, 9(2), 96-108.

Carter, J. (1997). Foreword. In S. B. Levy \& V. W. Sidel (Eds.), War and public health. New York: Oxford University Press.

Checkoway, B. N., \& Gutierrez, L. M. (2008). Youth participation and community change. Journal of Community Practice, 14(1), 1-9. https://doi.org/10.1300/J125v14n01_01

Creswell, J. W., \& Plano Clark, V. L. (2011). Designing and conducting mixed methods research (2 ed.). Thousand Oaks, CA: Sage Publications.

Crossley, M., \& Broadfoot, P. (1992). Comparative and international research in education: Scope, problems and potential. British Educational Research Journal, 18(2), 99-112. https://doi.org/10.1080/0141192920180201

Department for International Development DFID. (2014). Disability framework: Leaving no one behind. Retrieved from https://www.add.org.uk/sites/default/files/DFID_Disability-Framework-2014.pdf

Department for International Development DFID. (2015). Disability framework: Leaving no one behind. Retrieved from

https://www.gov.uk/government/uploads/system/uploads/attachment_data/file/554802/DFID-Disability-Fra mework-2015.pdf

Department for International Development. (2000). Realizing human rights for poor people: Target strategy paper. Retrieved from http://www2.ohchr.org/english/issues/development/docs/human_rights_tsp.pdf

Deutsche Gesellschaft fur Technische Zusammenarbeit (GTZ). (2005). Guidelines on capacity building in the regions module B: Methods and instruments for the capacity building cycle. Version 2.0 February 2005 GTZ- SfDM support for decentralization measures. Retrieved from http://www.bvsde.paho.org/bvsacd/cd32/poppe.pdf

Eide, A. H., \& Ingstad, B. (2013). Disability and poverty: Reflections on research experiences in Africa and beyond. African Journal of Disability, 2(1), 1-7. https://doi.org/10.4102/ajod.v2i1.31

Forge, W. H. (1997). Arms and public health: A global perspective. In S. B. Levy \& V. W. Sidel (Eds.), War and public health (pp. 3-11). New York: Oxford University Press.

Friesen, M. N., Krassikouva-Enns, O., Ringaert, L., \& Isfeld, H. (2010). Community support systems for farmers who live with disability. Journal of Agromedicine, 15(2), 166-174. https://doi.org/10.1080/10599241003630569

Grant, G., Ramcharan, P., \& Flynn, M. (2007). Resilience in families with children and adult members with intellectual disabilities: Tracing elements of a psycho-social model. Journal of Applied Research in Intellectual Disabilities, 20, 563-575. https://doi.org/10.1111/j.1468-3148.2007.00407.x

Gukande, M., Jombwe, J., Fualal, J., \& Gakwaya, A. (2009). Boda-boda injuries a health problem and a burden of disease in Uganda: A tertiary hospital survey. East Central African Journal of Surgery, 14(2), 33-37.

Head, B. W. (2008). Community engagement: Participation on whose terms? Australian Journal of Political Science, 42(3), 441-454. https://doi.org/10.1080/10361140701513570

Lewis, L. (2010). Geographies of disabilities, resilience and social justice. Political Crossroads, 17(1), 75-87. https://doi.org/10.7459/pc/17.1.07

Lwanga-Ntale, C. (2003). Chronic poverty and disability in Uganda. Development Research and Training. Retrieved from http://digitalcommons.ilr.cornell.edu/gladnetcollect

Milner, A., Aitken, Z., Krnjacki, L., Bentley R., Blakely, T., LaMontagne, A. D., \& Kavanagh, A. M. (2015). Perceived fairness of pay among people with and without disabilities: a propensity score matched analysis of working Australians. Scandinavian Journal of Work, Environment \& Health, 41(5), 451-459. https://doi.org/10.5271/sjweh.3515

Mpofu, J., \& Shumba, A. (2013). Disabilities and entrepreneurship in Makonde rural community in Zimbabwe. Studies of Tribes and Tribals, 11(2), 135-144. https://doi.org/10.1080/0972639X.2013.11886675 
Niglas, K. (2010). The multidimensional model of research methodology: An integrated set of continua. In A. Tashakkori \& C. Teddlie (Eds.), SAGE handbook of mixed methods in social \& behavioral research. Thousand Oaks, CA: Sage Publications.

Onwuegbuzie, A. J., \& Collins, K. M. T. (2007). A typology of mixed methods sampling designs in social science research. The Qualitative Report, 12(2), 281-316.

Pagan-Rodriguez, R. (2015). Disability, training and job satisfaction. Social Indicators Research, 122, 865-885. https://doi.org/10.1007/s11205-014-0719-2

Phillips, D., Waddington, H., \& White, H. (2014). Better targeting of farmers as a channel for poverty reduction: a systematic review of farmer field schools targeting, Development Studies Research, 1(1), 113-136. https://doi.org/10.1080/21665095.2014.924841

Pigg, K. (1999). Community leadership and community theory: A practical synthesis. Community Development Society Journal, 30(2), 196-212. https://doi.org/10.1080/15575339909489721

Rwakakamba, M., \& Lukwago, D. (2014). The changing face of NAADS and what the entry of Uganda People's Defence Forces will mean for Uganda's agriculture. Public policy issue paper, 004, 1-14. Retrieved from http://www.agencyft.org/

Saldana, J. (2008). The coding manual for qualitative researchers. Thousand Oaks, CA: Sage.

Sherry, R. A. (1969). A ladder of citizen participation. Journal of the American Institute of Planners, 35(4), 216-224. https://doi.org/10.1080/01944366908977225

Siddiqua, K. A., Islam, R., \& Afrin, S. (2012). Disability, employment and poverty: A Study of the physically handicapped people in Dhaka City. ME-JAA Middle East Journal of Age and Ageing.

The Republic of Uganda \& UNICEF. (2014). Children with disabilities living in Uganda: Situational analysis on the rights of children with disabilities in Uganda.

Uganda Bureau of Statistics. (2015). Statistical abstracts.

UNESCO. (2018). Education and disability: Analysis of data from 49 countries. Information paper, 49. Retrieved from http://uis.unesco.org/en/news/education-and-disability-analysis-data-49-countries

Urdan, T. C. (2010). Statistics in plain English (3rd ed.). New York: Routledge, Tylor and Francis Group. https://doi.org/10.4324/9780203851173

Vornholt, K., Uitdewilligen, S., \& Nijhuis, F. J. N. (2013). Factors affecting the acceptance of people with disabilities at work: A literature review. Journal of Occupational Rehabilitation, 23, 463-475. https://doi.org/10.1007/s10926-013-9426-0

Wagner III, J. A. (1994). Participation's effects on performance and satisfaction A Reconsideration of research evidence. Academy of Management Review, 19(2), 312-330. https://doi.org/10.5465/amr.1994.9410210753

Whelan, S., Ruane, D. J., McNamara, J., Kinsella, A., \& McNamara, A. (2009). Disability on Irish Farms - A real concern. Journal of Agromedicine, 14(2), 157-163. https://doi.org/10.1080/10599240902813078

Wilkinson, K. (1991). The community in rural America. New York, NY: Greenwood Press.

Wolbring, G., Mackay, R., Rybchinskin, T., \& Noga, J. (2013). Disabled people and the post-2015 development goal agenda through a disability studies lens. Sustainability, 5, 4142-4182.

https://doi.org/10.3390/su5104152

World Health Organization. (1991). Community involvement in health development Challenging health services. WHO Technical Report Series, 809, 1-56. Retrieved from http://apps.who.int/iris/bitstream/10665/40624/1/WHO_TRS_809.pdf

World Health Organization. (2008). Social determinants of health: Social participation. Retrieved from http://www.who.int/gender-equity-rights/understanding/participation-definition/en/

World Health Organization. (2018). Global status report on road safety. Retrieved from https://apps.who.int/iris/bitstream/handle/10665/277370/WHO-NMH-NVI-18.20-eng.pdf?ua=1

Yeo, R. (2005). Disability, poverty and the new development agenda. Disability KaR Knowledge and Research. Retrieved from http://hpod.org/pdf/Developmentagenda.pdf 


\section{Copyrights}

Copyright for this article is retained by the author(s), with first publication rights granted to the journal.

This is an open-access article distributed under the terms and conditions of the Creative Commons Attribution license (http://creativecommons.org/licenses/by/3.0/). 